\title{
The psychometric properties of the Childhood Health Assessment Questionnaire (CHAQ) in children with cerebral palsy
}

\author{
Soojung Chae ${ }^{1}$, Eun-Young Park ${ }^{1}$ and Yoo-Im Choi ${ }^{*}$
}

\begin{abstract}
Background: The evaluation of children with cerebral palsy (CP) focuses on activity level measurement to examine the effect of health-care interventions on their physical functioning in the home, school, and community settings. This study aimed to identify the psychometric properties of the Korean version of the Childhood Health Assessment Questionnaire (CHAQ) by applying the Rasch model. The use of the Rasch model has an advantage in that item characteristic curve estimation is not affected by the characteristics of subject groups.

Methods: Data were collected from 65 children with CP aged 75-190 months using the Korean version of the CHAQ. Response data were analyzed according to the Rasch model, and item fitness and difficulty and the appropriateness and reliability of the rating scale were evaluated.

Results: Among the 30 items of the Korean version of the CHAQ, two items (nail-cutting and opening a bottle cap that was already opened) were shown to be misfit items with low fitness. The analysis results for item difficulty indicated the requirement for modification of item difficulty, pointing out the need for the addition of question items with both higher and lower difficulty. The use of 4-point rating scale in the evaluation questionnaire was shown to be appropriate. With respect to analysis outcomes, the subjects' separation reliability value and separation index were 0.97 and 5.92, respectively. In contrast, the separation reliability value and separation index for the question items were 0.95 and 4.51 , respectively.
\end{abstract}

Conclusions: The results of this study suggest the need for the modification of item fitness and difficulty. The psychometric properties of the Korean version of the CHAQ were identified using the item response theory-based Rasch analysis.

Keywords: Children with cerebral palsy, Childhood health assessment questionnaire, Health-related quality of life, Rasch analysis

\section{Background}

Cerebral palsy $(\mathrm{CP})$ is a permanent and nonprogressive developmental disability. Despite medical treatment and rehabilitation, various motor limitations associated with $\mathrm{CP}$ may reduce functionality and affect skills required for the performance of activities of daily living (ADLs) [1]. Premature mortality in children with $\mathrm{CP}$ is rapidly decreasing,

\footnotetext{
* Correspondence: tiffaniey@wku.ac.kr

${ }^{2}$ Department of Occupational Therapy, School of Medicine and Institute for Health Improvement, Wonkwang University, Iksan, South Korea

Full list of author information is available at the end of the article
}

and most of them survive until adulthood [2,3]. The acquisition of high-level information about the functional status of children with $\mathrm{CP}$ has progressively become imperative $[4,5]$. However, information on health-related quality of life (HRQL) in children with $\mathrm{CP}$, which could provide critical perspectives in preparation for the future of these children, remains lacking [6].

Unlike in the past, the evaluation of children with $\mathrm{CP}$ focuses on activity level measurement to examine the effect of health-care interventions on their physical functioning in the home, school, and community settings $[7,8]$. The

(c) The Author(s). 2018 Open Access This article is distributed under the terms of the Creative Commons Attribution 4.0 International License (http://creativecommons.org/licenses/by/4.0/), which permits unrestricted use, distribution, and 
International Classification of Functioning (ICF) has provided a framework for the collection of data on aspects of activity limitation and impairment, urging the exploration of the correlation between activity limitation and impairment. The ICF defines activity as the execution of any specific task by an individual [9]. When assessing disability, all relevant circumstances must be taken into account, and the extent to which individuals with disabilities can perform essential functions or major life activities should be measured.

Recently, evaluation has included the role of childhood or how children with disabilities feel in the course of solving obstacles that they face [10-12]. HRQL, a concept pertaining to aspects of life quality that are directly associated with health status, has been assessed $[13,14]$. A HRQL assessment inventory had been developed for the past 10 years, with some general scales of HRQL having already been applied to children with disabilities and used for the evaluation of physical and psychological damage [15-18]. Various assessment inventories have been adapted in Korea, including the Korean version of EuroQol-5 Dimensions, which is designed to assess health status with respect to five areas of HRQL, namely mobility, self-care, usual activities, pain/discomfort, and anxiety/depression. The indices for each area are substituted with the assessment index equation to calculate the subjective HRQL indices [19, 20]. The Korean version of the 12-item Short Form Health Survey developed for the Medical Outcomes Study is also a tool used to measure HRQL and comprises physical and mental component summaries (12 items in total), with a higher score indicating a higher HRQL level. Moreover, the entire inventory was reported to be reliable (Cronbach's $\alpha=$ 0.810) [21]. The Korean version of the World Health Organization (WHO) Quality of Life Scale, an abbreviated modified version of the WHO Quality of Life Assessment Instrument-100 translated into Korean [22], is a 5-point scale inventory consisting of four domains (physical health, psychological, social, and environmental) for each of 24 facets related to quality of life. A response of "never" and "always" corresponds to a score of 1 point (lowest score) and 5 points (highest score), respectively.

These assessment tools have been used to evaluate HRQL in children with different types of disabilities. Based on the results, various plans have been proposed, and assistance has been recommended and provided. However, general scales for HRQL do not directly address functionality or ADL-related concepts, with only few tools among several scales being suitable for children with $\mathrm{CP}$ [23-25]. In particular, there remains a lack of information about HRQL in children with CP in Korea, possibly owing to the absence of feasible tools for HRQL measurement.

Recently, the Childhood Health Assessment Questionnaire (CHAQ), a tool specially developed for the assessment of functional capacity and independence in everyday life, has been utilized in children with CP. The CHAQ is a validated questionnaire comprising specific items used to evaluate juvenile idiopathic arthritis in children and adolescents [26] and has been considerably applied to patients with current mobility restrictions due to other chronic diseases such as pediatric spondyloarthropathies, spina bifida, joint hypermobility syndrome, and systemic lupus erythematosus [27-31]. The CHAQ has already been translated into several languages and used in many countries [32]. In Korea, the CHAQ was adapted by Park [33]; since then, its usefulness for the health-related assessment of children with $\mathrm{CP}$ has been reported.

The rapidly growing development of comprehensive question items to measure functional health status and quality of life in children has left a task of whether measurement of general aspects or specific conditions should be considered in selecting a tool [34-36]. The tool should provide appropriate information, and its psychometric properties could be measured to check its validity. Further, the tool can be selected only when it is practical, reliable, and appropriate and is able to measure change or sensitive to the change [37].

The classical method of scale verification is to confirm construct validity using factor analysis. However, determining the construct validity of the scale by factor analysis is limited because it is not a confirmation at the level of question [38]. The scale verified by factor analysis is occasionally adapted in other cultural regions in the course of its utilization and is applied to other groups with different characteristics from the respondent group participating in scale development. As scales are diversely utilized, an argument emerges from a study on scale development that factor analysis itself cannot accurately evince validity [39]. Therefore, in order to accurately estimate the fitness and difficulty of items derived from factor analysis, attempts to verify them using various statistical methods are required.

Among these attempts, the Rasch model is one of the item response theory models increasingly used as an appropriate research method for the assessment of the appropriateness of item fitness and difficulty [40]. When measuring the ability of a subject using traditional methods, the same subject will attain a higher and lower score if administered with a lower and higher level of test, respectively. In other words, in traditional methods, the characteristics of children with $\mathrm{CP}$ could affect ability measurement, possibly influencing the validity analysis of measurement tools. As the psychometric properties of an instrument can vary among different population groups and can be particularly affected by the cultural context, a systematic assessment of psychometric properties is imperative before an instrument can become extensively used within a specific patient population [41]. 
Therefore, in order to evaluate the psychometric properties of the CHAQ for assessing HRQL in children with CP in Korea, it is necessary to use data obtained from Korean children with CP. An item response theory-based analysis could be utilized to scrutinize question items using the item characteristic curve unique for each item, examine the difficulty and discrimination power of each item, and estimate the real ability of the subject based on analysis results. In addition, the use of the Rasch model has an advantage in that item characteristic curve estimation is not affected by the characteristics of subject groups [42]. Although the suitability of the Korean version of the CHAQ as a tool based on the classical test theory has already been confirmed in a validity testing study [33], attempting to verify the nature of question items by applying the Rasch model based on the item response theory remains essential to accurately evaluate item fitness and difficulty.

Therefore, this study aimed to identify the psychometric properties of the Korean version of the CHAQ in children with CP by applying the Rasch model. In view of the objective of this study, the following specific research questions were raised: First, is the item fitness of the Korean version of the CHAQ appropriate for children with CP? Second, is the item difficulty of the Korean version of the CHAQ appropriate for children with $\mathrm{CP}$ ? Third, are the response categories of the Korean version of the CHAQ appropriate for children with $\mathrm{CP}$ ? Fourth, is the Korean version of the CHAQ reliable when used in children with $\mathrm{CP}$ ?

\section{Methods}

\section{Subjects}

For subject recruitment, the researchers sent letters to professionals at a hospital or community welfare center, asking for referrals of eligible subjects. Initially, 73 children with CP desired to participate in this study. Subsequently, the researchers sent letters describing the details of this study and received 65 informed consent forms for participation from the parent(s) of children with CP. As incentive, gift cards equivalent to approximately 20,000 won each were provided to the subjects' parent(s) and therapists. School-age children diagnosed with spastic CP who provided parent consent for their participation in the study were included, whereas those who underwent elective dorsal rhizotomy and had spina bifida and associated musculoskeletal disorders such as muscular dystrophy and myopathy were excluded from the study. Evaluation was performed by one physiotherapist and one caregiver per one child with $\mathrm{CP}$ for over 6 months of treatment. The general characteristics of children with CP are summarized in Table 1. The mean age of subjects in this study was 113.14 months (standard deviation $=30.03$; range, 75-190 months) $($ Table 1$)$.
Table 1 General characteristics of the study subjects

\begin{tabular}{llll}
\hline Classification & & Number & $\%$ \\
\hline Gender & Male & 45 & 69.2 \\
Site of Palsy & Female & 20 & 30.8 \\
& Quadriplegia & 15 & 23.1 \\
& Triplegia & 4 & 6.2 \\
& Paraplegia & 28 & 43.1 \\
& Hemiplegi & 15 & 23.1 \\
& Missing Data & 3 & 4.6 \\
Type & Spastic & 53 & 81.5 \\
& Athetoid & 9 & 13.8 \\
& Hypotensive & 1 & 1.5 \\
Gross Motor Function & Combined Type & 2 & 3.1 \\
Classification System & Level 1 & 16 & 24.6 \\
& Level 2 & 14 & 21.5 \\
& Level 3 & 10 & 15.4 \\
& Level 4 & 6 & 9.2 \\
Total & Level 5 & 19 & 29.2 \\
& & 65 & 100 \\
\hline
\end{tabular}

\section{Tools}

\section{Childhood health assessment questionnaire}

The CHAQ is a tool developed to assess health status and HRQL in children and adolescents with juvenile idiopathic arthritis. It has already been applied to children with various types of disabilities to measure their functional capacity and independence in performing ADLs during the previous week at evaluation time point. The CHAQ covers the following eight domains: dressing and grooming, standing, eating, walking, hygiene, hand stretch, catching, and activities. Items in these respective areas are rated on a 4-point rating scale, with score ranging from 0 to 3 points. A score of 0,1 , or 2 points denotes the performance of certain tasks without difficulty, with some difficulty, and with much difficulty, respectively, whereas a score of 3 points suggests inability to execute tasks. Because some questions are not applicable to young children, such item is marked as "not applicable." A higher score means low functional capacity. The CHAQ includes two visual analogue scales for the evaluation of overall well-being and pain severity. The eight domains are evaluated with the highest score for the detailed items being recorded, and the overall average is interpreted using the CHAQ Disability Index, with 0 point and 3 points indicating the absence of disability and presence of serious physical disability, respectively [32]. In calculating the CHAQ Disability Index, the highest score for the subquestions under each area is selected. A score of at least 2 points is indicated when a child requires some help in performing 
certain activities, and the average score for each area is considered the value for the CHAQ Disability Index. In this study, we used the CHAQ adapted to the Korean population [33].

\section{Gross motor function classification system}

The Gross Motor Function Classification System (GMFCS) was used for the evaluation of gross motor function in children with CP. The GMFCS, a tool designed to evaluate motor disorders in children with $\mathrm{CP}$, categorizes these children into the following five levels: level 1 children, or those who can walk without restrictions; level 2 children, or those who walk with some limitations in most settings; level 3 children, or those who may walk without physical assistance but are using handheld crutches, canes, or walkers; level 4 children, or those who can move around with some limitations by themselves using electric-powered wheelchair or other means of transportation in most settings; and level 5 children, or those who have seriously limited ability to move around by themselves even with the use of assistive devices [43].

\section{Procedures}

Measured data from a total of 65 children with $\mathrm{CP}$ who provided informed consent for their participation in this study were collected to determine the psychometric properties of the CHAQ. In this study, a secondary analysis of data collected from a structural equation modeling study on factors affecting the participation of children with CP in daily life activities was performed [44]. The GMFCS was used by a physiotherapist with experience in treating children over 6 years, whereas the CHAQ was used by a caregiver.

\section{Data processing}

An infit mean square statistic (MNSQ) value $<0.5$ or $>1.7$ for each item denoted unacceptable item fitness [42]. The relation between individual attribute scores and item difficulty was analyzed using the distributions of items and subjects, which were included in a graph according to respective individual attribute scores to enable a direct comparison. Because the individual attribute scores and item difficulty were correspondingly converted into a logit scale for a direct comparison, it was possible to evaluate whether the item difficulty was appropriate for the analyzed group. When the ranges of two different distributions were consistent (i.e., similar distribution ranges for item difficulty such that item difficulty measurement could estimate all ranges of individual attribute scores), the distribution was considered sufficient [45].

The rating scale was analyzed using changes in threshold and the fit index of each subject for each rating score. In general, the higher the rating scores, the higher the proficiency estimates and threshold were for subjects who responded to the questionnaire.

In Rasch analysis, the standard error of measurement is calculated based on all proficiency estimates apart from that of the sample group. This is shown as two concepts, namely the subject separation index and the item separation index. A larger value for these two separation indices indicates an accurate functional measurement level [42]. Based on these concepts, changes in separation reliability were drawn through removal of misfit items and subjects who inadequately responded. A total of 14 subjects inadequately responded in this study.

We used WINSTEPS version 3.6 [46] as statistical software to adapt the Korean version of the CHAQ and apply the Rasch model.

\section{Results}

\section{Item fitness}

The estimation results for the fitness of the 30 items of the CHAQ are summarized in Table 2. As shown in Table 2, the infit MNSQ value for items 4 and 23 following estimation of fitness among all items of the CHAQ was $>1.7$ and $<0.5$, respectively. After estimating the fitness of all items, the result for the fitness of four items among the 30 items of CHAQ indicated an infit MNSQ value of $>1.7$, whereas the infit MNSQ value for item 23 was $<0.5$ (Table 2).

\section{Item difficulty}

In the comparison of individual attribute scores and item difficulty, items 20 and 1 appeared to have the highest and lowest difficulty, respectively. Moreover, proficiency estimates were higher and lower than item difficulty in 22 and 24 subjects, respectively (Fig. 1).

\section{Rating scale analysis}

The estimation results for the 4-point rating scale of the CHAQ are shown in Table 3 and Fig. 2. The analysis results indicated that, for the CHAQ adapted to the Korean population, the increase in scale scores corresponded to an increase in the average proficiency estimate in subjects. Furthermore, the fit index for each scale score provided information on whether the rating scale was properly functioning. The fit index for the individual scale scores showed values $\geq 1.3$ with respect to a value of 1.0 , implying that the applicable scale was not properly functioning. The results of the analysis performed showed that there was no misfit scale in the CHAQ. With an increase in each estimate, similar to that in the average proficiency estimate in subjects, the threshold must show an increasing tendency as well. The analysis of the scale threshold showed that the threshold was proportional to the increase in scale scores in all subscales. 
Table 2 Item fit statistics: entry order

\begin{tabular}{|c|c|c|c|c|c|c|}
\hline \multirow[t]{2}{*}{ Item } & \multirow[t]{2}{*}{ Measure } & \multirow[t]{2}{*}{ S.E. } & \multicolumn{2}{|l|}{ Infit } & \multicolumn{2}{|l|}{ Outfit } \\
\hline & & & MNSQ & Z-value & MNSQ & Z-value \\
\hline 1 & 29.93 & 2.42 & 1.03 & 0.20 & 0.88 & 0.00 \\
\hline 2 & 33.73 & 2.40 & 0.58 & -2.20 & 0.54 & -0.70 \\
\hline 3 & 58.70 & 2.76 & 0.84 & -0.60 & 1.00 & 0.10 \\
\hline 4 & 27.59 & 2.43 & 2.28 & 4.30 & 1.93 & 1.40 \\
\hline 5 & 57.20 & 2.73 & 1.20 & 0.80 & 0.88 & -0.20 \\
\hline 6 & 61.83 & 2.84 & 1.27 & 1.10 & 0.73 & -0.60 \\
\hline 7 & 36.62 & 2.41 & 1.54 & 2.20 & 1.24 & 0.60 \\
\hline 8 & 64.29 & 2.90 & 0.69 & -1.20 & 0.81 & -0.30 \\
\hline 9 & 48.85 & 2.56 & 1.54 & 2.10 & 1.70 & 1.80 \\
\hline 10 & 48.20 & 2.55 & 1.39 & 1.60 & 1.05 & 0.30 \\
\hline 11 & 42.55 & 2.47 & 1.70 & 2.70 & 1.35 & 0.90 \\
\hline 12 & 41.94 & 2.46 & 0.64 & -1.80 & 0.66 & -0.80 \\
\hline 13 & 48.20 & 2.55 & 0.64 & -1.70 & 0.50 & -1.60 \\
\hline 14 & 57.20 & 2.73 & 0.56 & -2.10 & 0.44 & -1.90 \\
\hline 15 & 55.73 & 2.69 & 0.67 & -1.50 & 0.57 & -1.30 \\
\hline 16 & 50.17 & 2.58 & 0.61 & -1.90 & 0.54 & -1.50 \\
\hline 17 & 58.70 & 2.76 & 1.22 & 0.90 & 1.49 & 1.30 \\
\hline 18 & 58.70 & 2.76 & 0.80 & -0.80 & 0.61 & -1.10 \\
\hline 19 & 56.46 & 2.71 & 0.62 & -1.70 & 0.58 & -1.30 \\
\hline 20 & 73.40 & 3.16 & 0.98 & 0.00 & 2.12 & 1.50 \\
\hline 21 & 64.29 & 2.90 & 0.72 & -1.10 & 0.87 & -0.10 \\
\hline 22 & 59.47 & 2.78 & 0.82 & -0.70 & 0.79 & -0.50 \\
\hline 23 & 65.99 & 2.94 & 0.47 & -2.40 & 0.79 & -0.30 \\
\hline 24 & 62.64 & 2.85 & 0.68 & -1.30 & 0.76 & -0.50 \\
\hline 25 & 62.64 & 2.85 & 0.58 & -1.80 & 0.78 & -0.40 \\
\hline 26 & 36.04 & 2.41 & 0.93 & -0.30 & 0.78 & -0.20 \\
\hline 27 & 36.04 & 2.41 & 0.87 & -0.50 & 0.67 & -0.50 \\
\hline 28 & 36.62 & 2.41 & 0.47 & 1.90 & 1.14 & 0.40 \\
\hline 29 & 32.02 & 2.39 & 1.08 & 0.40 & 0.98 & 0.20 \\
\hline 30 & 34.31 & 2.40 & 1.43 & 1.80 & 1.11 & 0.40 \\
\hline
\end{tabular}

MNSQ Mean Square, SE Standard Error

\section{Separation reliability}

The separation reliability of the CHAQ adapted to the Korean population is shown in Table 4.

The subjects attained a separation reliability value of 0.97 and separation index of 5.92, whereas the separation reliability value and separation index for the items were 0.95 and 4.51, respectively.

\section{Discussion}

This study aimed to identify the fitness and difficulty of the CHAQ items adapted to the Korean population and verify the appropriateness and reliability of the rating scale in children with CP. To address such objectives,

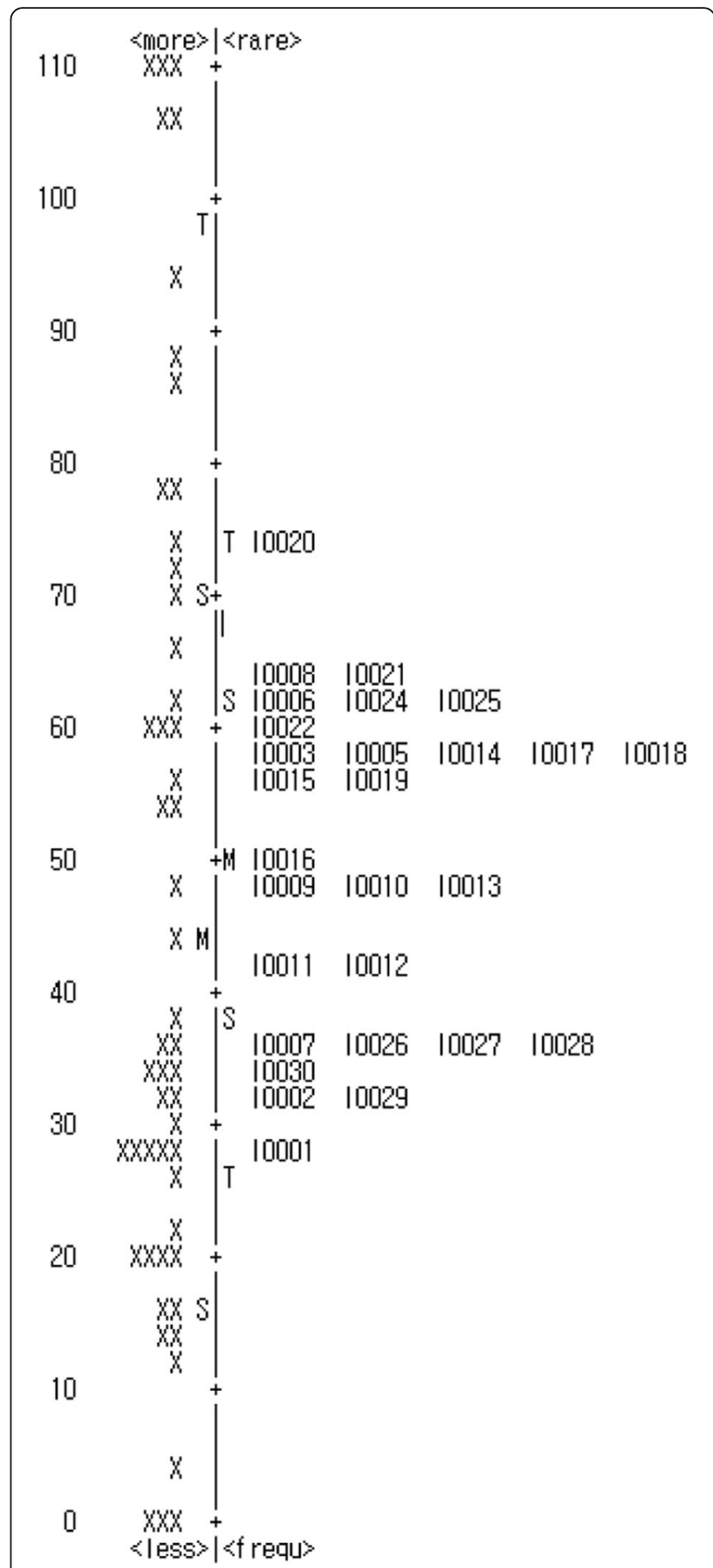

Fig. 1 Map of personal proficiencies and item difficulties for the 28 items of the Childhood Health Assessment Questionnaire

Rasch analysis of 65 subjects was performed using the CHAQ adapted to the Korean population.

When the fitness of the CHAQ items was determined, 2 of 30 items were shown to be misfit items. Item fitness is used to confirm the unidimensional nature of test items and is estimated using the MNSQ value via the utilization of the rating scale model, which could reveal 
Table 3 Summary of the rating scale analysis of original 4 point scale

\begin{tabular}{lllll}
\hline $\begin{array}{l}\text { Category } \\
\text { Level }\end{array}$ & $\begin{array}{l}\text { Observed } \\
\text { Average }\end{array}$ & $\begin{array}{l}\text { Infit } \\
\text { MNSQ }\end{array}$ & $\begin{array}{l}\text { Outfit } \\
\text { MNSQ }\end{array}$ & $\begin{array}{l}\text { Structure } \\
\text { Calibration }\end{array}$ \\
\hline 0 & -33.19 & 0.92 & 0.95 & None \\
1 & -11.77 & 1.02 & 1.01 & -17.48 \\
2 & 8.18 & 0.87 & 0.70 & 1.50 \\
3 & 33.06 & 1.31 & 1.26 & 15.95 \\
\hline
\end{tabular}

how each item is adequately configured to confirm its unidimensional nature. A high MNSQ value indicates that the item does not have homogeneity with other items within the scale. In contrast, a low value means that the item is redundant with other items [45]. The MNSQ presents two values: the infit index and the outfit index. The infit and outfit indices are standardized, with the standardized value presented as $\mathrm{Z}$ value. In the Rasch model, an MNSQ value of 1 represents an ideal value. In this study, each item with an infit index $<0.5$ or $>1.7$ was regarded as a misfit item in order to determine item fitness [42]. Item 4, which pertained to nail-cutting, had an infit index $\geq 1.7$, whereas item 23 , which involved opening a bottle cap that was already opened, had an infit index $\leq 0.5$.

Difficulties associated with the use of the CHAQ adapted to the Korean population were analyzed by comparing individual attribute scores and item difficulty. When the distribution ranges of the individual attribute scores and item difficulty were consistent (i.e., similar distribution ranges for item difficulty such that item difficulty measurement could estimate all ranges of individual attribute scores), the distribution was considered sufficient [45]. The analysis results indicated that the difficulty for item 1 (tying shoe laces and buttoning) was the lowest among the 28 items with low fitness, whereas the difficulty for item 20 (turning the head to see behind the shoulder) was the highest. With respect to item difficulty for the CHAQ adapted to the Korean population, $23.5 \%$ and $13.7 \%$ of children showed a lower and higher capacity, respectively. A high percentage of floor effect for the measurement tool indicates that the item difficulty is higher than the proficiency estimate assessed using a tool in subjects. Conversely, a high percentage of ceiling effect for the measurement tool indicates that the item difficulty is lower than the proficiency estimate in subjects; hence, it is impossible to assess subjects exhibiting higher proficiency estimates as the item difficulty is too low. In the study of Park [33], the percentage of floor effect was reported to be 4.3-38.6\%, with the rate for standing, walking, hand stretching, and catching exceeding $20 \%$. In the case of ceiling effect, the percentage of floor effect was reported to be $1.4-25.7 \%$, with the rate for walking and hygiene exceeding $20 \%$. In the study of Morales et al. [32], the percentage of floor and ceiling effects was reported to be 2.1$26.0 \%$ and $30.2-68.8 \%$, respectively. The high percentage of ceiling effect in the study of Morales et al. [32] should be considered, as the proportion of level 1 subjects according to the GMFCS was high (37.5\%), and the results of Park's study [33] should had been affected by the fact that the proportion of level 1 children was $22.2 \%$. Unlike in previous studies that identified item difficulty based on

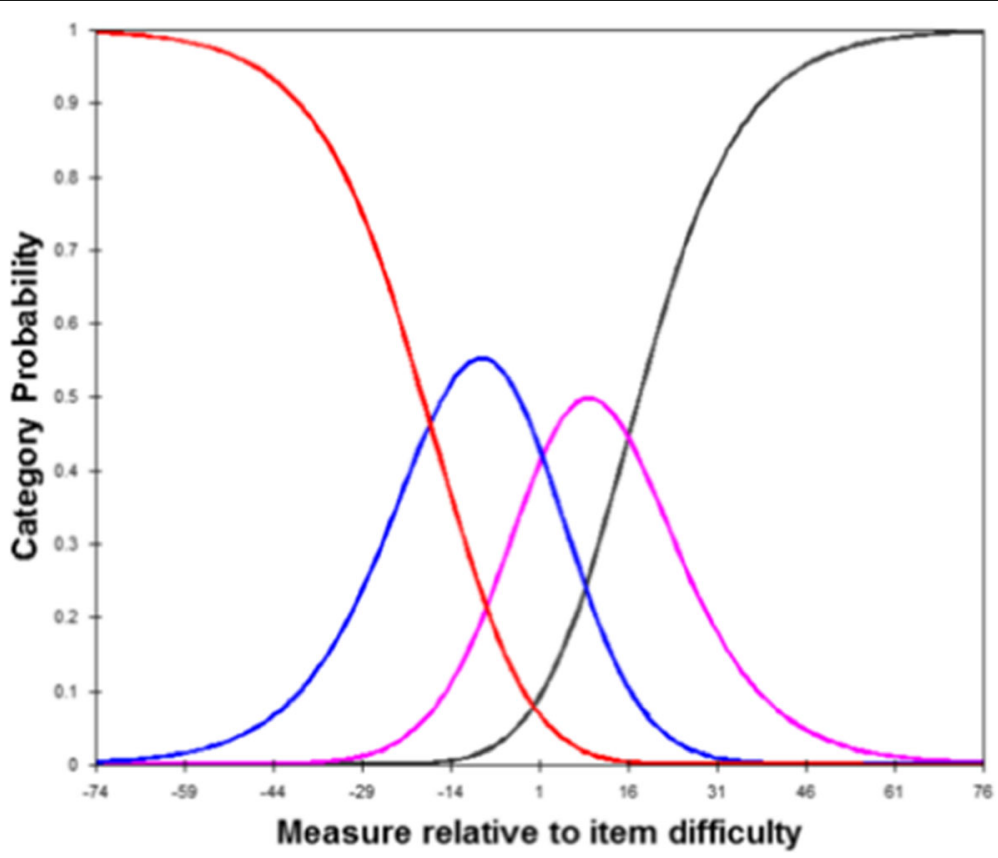

Fig. 2 Category probability curve for the Childhood Health Assessment Questionnaire 
Table 4 Separation Reliability of the Study Subjects and the Items

\begin{tabular}{lllll}
\hline & Mean & $\begin{array}{l}\text { Standard } \\
\text { Deviation }\end{array}$ & $\begin{array}{l}\text { Separation } \\
\text { Reliability }\end{array}$ & $\begin{array}{l}\text { Separation } \\
\text { Index }\end{array}$ \\
\hline Subjects & 34.0 & 26.8 & .97 & 5.92 \\
Items & 67.3 & 18.0 & .95 & 4.51 \\
\hline
\end{tabular}

the classical test theory, the subjects' proficiency estimates and item difficulty in this study were converted into logit interval scales and analyzed, making it possible to overcome the limitations of subjects. Nevertheless, the results of this study showed that there was a need to add items characterized by both high and low difficulty to the CHAQ adapted to the Korean population.

The rating scale to be used for the development of a test should have a clear response level as same as potential variables to be measured and used to produce a test with a rating scale shall have a clear response level. Furthermore, fit indices for each scale score provide information on whether the rating scale is properly functioning. The fit index for the individual scale scores showed values $\geq 1.5$ with respect to a value of 1.0, implying that the applicable scale was not properly functioning and providing possible information on whether the scale scores could be merged later $[46,47]$. In the analysis, the 4-point rating scale of the CHAQ adapted to the Korean population was determined to be appropriate. The scale threshold estimate showed a tendency similar to that of the average proficiency estimate in which the scale threshold increased with an increase in scale scores. The scale threshold estimate differs from the average proficiency estimate in subjects in that the former is an estimate calculated by observation frequency based on the sample, whereas the latter is an estimate calculated using the Rasch model [42]. The analysis results showed that the rating scale of the Korean version of the CHAQ is proportional to the increase in scale score, indicating that the response range was appropriate.

The Rasch analysis estimates two types of separation reliability: subject separation reliability and item separation reliability. The Rasch model is able to estimate the concurrent validity through the subject separation reliability and estimate the construct validity through the item separation reliability [48]. The subject separation reliability is the same concept as the conventional reliability, Cronbach's $\alpha$ [46]. When the CHAQ separation reliability was estimated after excluding the misfit subjects and misfit topics, the subject separation reliability was 0.97 , and the separation index was 5.92, whereas the item separation reliability was 0.95 , and the separation index was 4.51. These results showed the CHAQ adapted to the Korean population had a high level of reliability.
This study has some limitations. First, it would have been preferable to have more than 65 children with CP as subjects. Further study with a larger sample size is required to increase the power and possibility for generalization of study results. Second, this study only included children with CP aged 75-190 months. This could potentially affect the feasibility to generalize the results to the entire pediatric population with CP. Future studies on infants $(0$ 36 months) and/or young children (36-72 months) with $\mathrm{CP}$ should be performed. Lastly, this study did not examine differential item functioning. There may be items that function differently depending on the type of $\mathrm{CP}$; hence, further analysis based on the types of $\mathrm{CP}$ is required.

\section{Conclusions}

In this study, the results of assessment performed using the CHAQ adapted to the Korean population were analyzed using the Rasch model to determine the psychometric properties of the CHAQ as a tool for HRQL measurement in children with $\mathrm{CP}$. With the analysis, results for item fitness and difficulty, rating scale analysis, and reliability outcomes were derived. Based on the results, among the items of the CHAQ adapted to the Korean population, two items had low fitness, and modification of item difficulty was required. The rating scale was reliable and appropriate. Moreover, item development and modification were determined to be necessary to augment the usefulness of the CHAQ adapted to the Korean population in assessing HRQL in children with CP. Further studies clarifying the usefulness of tools in assessing quality of life in children with CP should be performed.

\section{Abbreviations}

ADLs: Activities of daily living; CHAQ: Childhood Health Assessment Questionnaire; GMFCS: Gross Motor Function Classification System; HRQL: Health-related quality of life; ICF: International Classification of Functioning; MNSQ: Mean square statistic; WHO: World Health Organization

\section{Funding}

This study was supported by Wonkwang University in 2017.

\section{Availability of data and materials}

The datasets used and/or analyzed during the current study are available from the corresponding author on reasonable request.

\section{Authors' contributions}

SC has made substantial contribution to the drafting of the manuscript. EY has made substantial contribution to data interpretation and analysis and drafting of the manuscript. YC has made substantial contribution to data collection and manuscript revision. All authors have read and approved the final version of the manuscript.

\section{Ethics approval and consent to participate}

The study was approved by the ethical review board of Jeonju University in Korea. All subjects provided written consent for their participation in the study.

\section{Consent for publication}

Not applicable.

\section{Competing interests}

The authors declare that they have no competing interests. 


\section{Publisher's Note}

Springer Nature remains neutral with regard to jurisdictional claims in published maps and institutional affiliations.

\section{Author details}

'Department of Secondary Special Education, College of Education, Jeonju University, 1200 3-ga, Hyoja-dong, Wansan-gu, Jeonju 560-759, South Korea. ${ }^{2}$ Department of Occupational Therapy, School of Medicine and Institute for Health Improvement, Wonkwang University, Iksan, South Korea.

Received: 12 June 2017 Accepted: 14 September 2018 Published online: 20 September 2018

\section{References}

1. Beckung E, Hagberg G. Neuroimpairments, activity limitations, and participation restrictions in children with cerebral palsy. Dev Med Child Neurol. 2002;44:309-16.

2. Hutton J, Pharoah PO. Life expectancy in severe cerebral palsy. Arch Dis Child. 2006;91:254-8

3. Katz RT. Life expectancy for children with cerebral palsy and mental retardation: implications for life care planning. NeuroRehabilitation. 2003;18:261-70.

4. Bottos M, Feliciangeli A, Sciuto L, Gericke C, Vianello A. Functional status of adults with cerebral palsy and implications for treatment of children. Dev Med Child Neurol. 2001:43:516-28.

5. Donkervoort M, Roebroeck M, Wiegerink D, van der Heijden-Maessen $H$, Stam H. Transition research group south West Netherlands. Determinants of functioning of adolescents and young adults with cerebral palsy. Disabil Rehabil. 2007;29:453-63.

6. Young NL, Rochon TG, McCormick A, Law M, Wedge JH, Fehlings D. The health and quality of life outcomes among youth and young adults with cerebral palsy. Arch Phys Med Rehabil. 2010;91:143-8.

7. Palisano RJ, Copeland WP, Galuppi BE. Performance of physical activities by adolescents with cerebral palsy. Phys Ther. 2007;87:77-87.

8. Schenker R, Coster W, Parush S. Participation and activity performance of students with cerebral palsy within the school environment. Disabil Rehabil. 2005;27:539-52.

9. Wold Health Organization. International classification of functioning disability and health. Geneva: World Health Organization; 2001.

10. Feldman BM, Grundland B, McCullough L, Wright V. Distinction of quality of life, health related quality of life, and health status in children referred for rheumatologic care. J Rheumatol. 2000;27:226-33.

11. Saigal S, Rosenbaum PL, Feeny D, Burrows E, Furlong W, Stoskopf BL, et al. Parental perspectives of the health status and health-related quality of life of teen-aged children who were extremely low birth weight and term controls. Pediatrics. 2000;105:569-74.

12. Sheridan RL, Hinson MI, Liang MH, Nackel AF, Schoenfeld DA, Ryan CM, et al. Long-term outcome of children surviving massive burns. JAMA. 2000; 283:69-73.

13. Bjornson KF, McLaughlin JF. The measurement of health-related quality of life (HRQL) in children with cerebral palsy. Eur J Neurol. 2001:8(Suppl 5): 183-93.

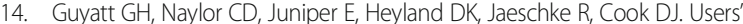
guides to the medical literature. XII How to use articles about health-related quality of life Evidence-Based Medicine Working Group. JAMA. 1997:277:1232-7.

15. Morales Nde M, Silva CH, Frontarolli AC, Araújo RR, Rangel VO, Pinto RM, et al. Psychometric properties of the initial Brazilian version of the CHQ-PF50 applied to the caregivers of children and adolescents with cerebral palsy. Qual Life Res. 2007;16:437-44.

16. Liptak GS, O'Donnell M, Conaway M, Chumlea WC, Worley G, Henderson RC, et al. Health status of children with moderate to severe cerebral palsy. Dev Med Child Neurol. 2001:43:364-70.

17. Vargus-Adams J. Health-related quality of life in childhood cerebral palsy. Arch Phys Med Rehabil. 2005;86:940-5.

18. Wake M, Salmon L, Reddihough D. Health status of Australian children with mild to severe cerebral palsy: cross-sectional survey using the child health questionnaire. Dev Med Child Neurol. 2003;45:194-9.

19. Kang IW, Cho WJ. The influence on mental health status and health-related quality of life in middle-aged women by the regular walking exercise by based on the Korea National Health and nutrition examination survey KNHANES VI. J Korean Soc Wellness. 2016;11:207-15.
20. Kim SY, Yun JE, Kimm HJ, Jee SH. The relation of physical activity by the IPAQ to health-related quality of life - Korea National Health and nutrition examination survey (KNHANES) IV 2007-2008. Korean J Health Educ Promot. 2011;28:15-25.

21. Lee S. A study on employees' health status and quality of life by using SF12: a case study of employees in large-scale workplaces in Daejeon and Chungcheong province. Seoul: Catholic University of Korea; 2010.

22. Min SK, Lee Cl, Kim Kl, Suh SY, Kim DK. Development of Korean version of WHO quality of life scale abbreviated version (WHOQOL-BREF). J Korean Neuropsychiatr Assoc. 2000;39:571-9.

23. Hammal D, Jarvis SN, Colver AF. Participation of children with cerebral palsy is influenced by where they live. Dev Med Child Neurol. 2004;46:292-8.

24. Nemer R, Blasco PA, Russman BS, O'Malley JP. Validation of a care and comfort hypertonicity questionnaire. Dev Med Child Neurol. 2006;48:181-7.

25. Schneider JW, Gurucharri LM, Gutierrez AL, Gaebler-Spira DJ. Health-related quality of life and functional outcome measures for children with cerebral palsy. Dev Med Child Neurol. 2001;43:601-8.

26. Machado CS, Ruperto N, Silva CH, Ferriani VP, Roscoe I, Campos LM, et al. The Brazilian version of the childhood health assessment questionnaire (CHAQ) and the child health questionnaire (CHQ). Clin Exp Rheumatol. 2001; 19:S25-9.

27. Brunner HI, Maker D, Grundland B, Young NL, Blanchette V, Stain AM, et al. Preference-based measurement of health-related quality of life (HRQL) in children with chronic musculoskeletal disorders (MSKDs). Med Decis Mak. 2003;23:314-22

28. Lam C, Young N, Marwaha J, McLimont M, Feldman BM. Revised versions of the childhood health assessment questionnaire $(\mathrm{CHAQ})$ are more sensitive and suffer less from a ceiling effect. Arthritis Rheum. 2004;51:881-9.

29. Moorthy LN, Harrison MJ, Peterson M, Onel KB, Lehman TJ. Relationship of quality of life and physical function measures with disease activity in children with systemic lupus erythematosus. Lupus. 2005;14:280-7.

30. Ruperto N, Malattia C, Bartoli M, Trail L, Pistorio A, Martini A, et al. Functional ability and physical and psychosocial well-being of hypermobile schoolchildren. Clin Exp Rheumatol. 2004;22:495-8

31. Selvaag AM, Lien G, Sørskaar D, Vinje O, Førre Ø, Flatø B. Early disease course and predictors of disability in juvenile rheumatoid arthritis and juvenile spondyloarthropathy: a 3 year prospective study. J Rheumatol. 2005;32:1122-30.

32. Morales NM, Funayama CA, Rangel VO, Frontarolli AC, Araújo RR, Pinto RM, et al. Psychometric properties of the child health assessment questionnaire (CHAQ) applied to children and adolescents with cerebral palsy. Health Qual Life Outcomes. 2008:6:109.

33. Park EY. Exploration of utility for Korean translation of the childhood health assessment questionnaire in children with cerebral palsy. J Spec Child Educ. 2010;12:335-53.

34. Lindström B, Eriksson B. Quality of life among children in the Nordic countries. Qual Life Res. 1993;2:23-32.

35. Taylor RM, Wray J, Gibson F. Measuring quality of life in children and young people after transplantation: methodological considerations. Pediatr Transplant. 2010;14:445-58.

36. Vogels T, Verrips GH, Verloove-Vanhorick SP, Fekkes M, Kamphuis R, Koopman HM, et al. Measuring health-related quality of life in children: the development of the TACQOL parent form. Qual Life Res. 1998;7:457-65.

37. Waters $E$, Salmon L, Wake M. The parent-form child health questionnaire in Australia: comparison of reliability, validity, structure, and norms. J Pediatr Psychol. 2000;25:381-91.

38. Embretson SE, Hershberger SL. The new rules of measurement: what every psychologist and educator should know. London: Psychology Press; 1999.

39. Hammond SM. An IRT investigation of the validity of non-patient analogue research using the Beck depression inventory. Eur J Psychol Assess. 1995;11:14-20.

40. Rasch G. Probabilistic models for some intelligence and attainment tests. Chicago: Mesa Press; 1993.

41. Kim JH, Park EY. Rasch analysis of the Center for Epidemiologic Studies Depression scale used for the assessment of community-residing patients with stroke. Disabil Rehabil. 2011;33:2075-83.

42. Bond TG, Fox CM. Applying the Rasch model: fundamental measurement in the human sciences. 3rd ed. New York: Routledge; 2015.

43. Morris C, Bartlett D. Gross motor function classification system: impact and utility. Dev Med Child Neurol. 2004:46:60-5.

44. Park EY. Factors contributing on participation in everyday activities for children with cerebral palsy: structural equation modeling. J Phys Mult Health Disabil. 2013:56:1-19. 
45. Hong S, Kim BS, Wolfe MM. A psychometric revision of the European American values scale for Asian Americans using the Rasch model. Meas Eval Couns Dev. 2005;37:194-207.

46. Linacre JM. WINSTEPS Rasch measurement computer program. Beaverton: Winsteps; 2006. http://www.winsteps.com/index.htm. Accessed 10 Aug 2018

47. Andrich D. A hyperbolic cosine latent trait model for unfolding polytomous responses: reconciling Thurstone and Likert methodologies. Br J Math Stat Psychol. 1996;49:347-65.

48. Wright BD, Masters GN. Rating scale analysis: Rasch measurement. Chicago: Mesa Press; 1982.

Ready to submit your research? Choose BMC and benefit from:

- fast, convenient online submission

- thorough peer review by experienced researchers in your field

- rapid publication on acceptance

- support for research data, including large and complex data types

- gold Open Access which fosters wider collaboration and increased citations

- maximum visibility for your research: over $100 \mathrm{M}$ website views per year

At BMC, research is always in progress.

Learn more biomedcentral.com/submissions 